\title{
EVIDENCE FOR CONTINUED EJECTION MODELS OF NOVAE
}

(Abstract)

M. FRIEDJUNG

Institut d'Astrophysique, Paris, France

New evidence has been obtained by calculating the sizes of regions emitting $\mathrm{H} \alpha$ and $\mathrm{Fe}$ II. The size of a region emitting a line can be calculated if it is optically thick and the ratio of upper to lower level populations is known. This calculation was performed for $\mathrm{H} \alpha$ in the case of Nova Delphini and for Fe II in RR Telescopii. Sizes of the emitting region were obtained which were, especially in the former case, much smaller than would be expected from instantaneous ejection models, indicating that most of the emission comes from a continuously ejecting region near the centre of the envelope. It is very important to continue high dispersion photometric studies of novae and such work on Nova Delphini is being continued in Paris by Malakpur. 